\title{
Trabalhonecessário
}

ISSN: 1808 - 799X

ANO 12, № 19 - 2014

\section{A EDUCAÇÃO E O EMBATE AOS PROBLEMAS SOCIAIS NA VISÃO DO EMPRESARIADO}

Mário Luiz de Souza ${ }^{1}$

\section{RESUMO}

Este artigo tem por objetivo apresentar os dados e as reflexões finais da tese para obtenção do grau de doutor, na Faculdade de Educação da Universidade Federal Fluminense, referente ao projeto de educação escolar presente nos artigos dos representantes do empresariado, publicados no jornal Folha de São Paulo no período do segundo governo do presidente Fernando Henrique Cardoso (19992002) e do primeiro governo do presidente Luiz Inácio Lula da Silva (2003-2006), abordando a questão dos problemas sociais. Tendo como pressuposto teórico e metodológico a matriz marxista, em especial o pensamento de Antonio Gramsci, analiso os artigos de representantes de três setores da economia brasileira (setor industrial, setor bancário e setor de comércio e serviço) partindo da hipótese de que são instrumentos políticos onde seus autores buscam criar um consenso ativo sobre suas propostas para o enfrentamento dos problemas sociais reinantes no nosso país. Nessa ação política, buscam legitimar a idéia de que a educação escolar é o principal caminho para resolução desse problema, mas para isso se faz necessário a participação direta do empresariado nesse processo, seja com a tese da responsabilidade social das empresas seja através da ação concreta do tripé: empresa privada, terceiro setor e o Estado.

Palavras chave: educação, empresariado, problemas sociais.

\section{THE EDUCATION AND THE CLASH OF THE SOCIAL PROBLEMS IN THE ENTREPRENEURS VISION}

\section{ABSTRACT}

1 Doutor em Educação, professor de História do Ensino Médio Integrado e do Mestrado Etnicorracial do CEFET-RJ. (maraols@uol.com.br) 


\section{Trabalhonecessário}

ISSN: 1808 - 799X

ANO 12, № 19 - 2014

This article haves the objective to show the data and the final reflections of the thesis to obtain the doctorship degree, at the Faculty of Education of Universidade Federal Fluminense, referring to the scholarship education project present in the representative entrepreneurs articles, published in Folha de São Paulo newspaper during the second Fernando Henrique Cardoso presidential government (199-2002) and the first Luiz Inácio Lula da Silva (2003-2006) presidential government, broaching the subject of the social problems.Having the marxist matrix as a theorical and methodological purpose, especially the Antonio Gramsci thoughts, I will analyzearticles from representatives of three Brazilian economy sectors (industrial, bank and commerce and services) starting from the hypothesis that they are political instruments which their authors try to create an active consensus about their proposals to face the social problems that rules our country. In this political action, they try to legitimate the idea that the scholarship education is the main course to solve this problem, but it seems necessary the direct participation oh the entrepreneurs in this process, or with the enterprises social responsibility thesis or with the concrete action of the tripod: private enterprise, third sector and State.

Key words: education, entrepreneurs, social problems.

\section{INTRODUÇÃO}

Marx e Engels nos alertam que no debate sobre a educação a vigorar numa dada sociedade seria um erro achar que essa temática estaria acima da luta de classes:

\footnotetext{
Vocês afirmam, porém, que queremos abolir os vínculos mais íntimos, na medida em que propomos substituir a educação doméstica pela social. Mas sua educação também não é determinada pela sociedade? Por acaso vocês não educam através de relações sociais, através de ingerência direta da sociedade, com ajuda das escolas, etc.? Os comunistas não inventaram a interferência da sociedade na educação; eles apenas modificam seu caráter e tiram a educação da influência da classe dominante.

O palavrório burguês sobre família e educação, sobre a relação estreita entre pais e filhos, torna-se tanto mais repugnante quanto mais a grande indústria rompe todos os laços familiares dos proletários e as crianças são transformadas em simples artigos de comércio e instrumentos de trabalho (MARX E ENGELS, 1998, p.25)
} 


\section{Trabalhonecessário}

ISSN: 1808 - 799X

ANO 12, № 19 - 2014

Seguindo a lógica exposta acima, vemos que a educação ${ }^{2}$ não pode ser vista como algo desprovido de neutralidade, tanto pelos conteúdos trabalhados como pela representação social que são reforçados juntos aos alunos. Sob essa perspectiva, esse trabalho tem por objetivo debater essa questão a partir dos artigos publicados pelos representantes do empresariado ${ }^{3}$ no jornal Folha de São Paulo, abordando a questão da educação e a resolução dos problemas sociais no Brasil, entre o período do segundo governo do presidente Fernando Henrique Cardoso (1999-2002) e o primeiro governo do presidente Luiz Inácio Lula da Silva (2003-2006).

Fruto da pesquisa que realizamos sobre o pensamento educacional do empresariado brasileiro, presente nos artigos dos representantes dessa classe dominante, publicados nos jornais O Globo e a Folha de São Paulo, entre 19992006, para obtenção do grau de doutor em educação ${ }^{4}$, esse artigo analisa a inserção da educação no projeto societário do empresariado, difundido na Folha, destacando sua função na configuração de uma nova sociabilidade no embate aos problemas sociais do país. O trabalho empírico e a análise efetuada sobre as nossas fontes primárias, demonstrou que os representantes desses componentes da classe dominante brasileira, buscou criar um consenso ativo, na sociedade civil

\footnotetext{
${ }^{2}$ Ao citarmos educação, ao longo desse artigo, estamos nos referindo a educação escolar.

${ }^{3}$ Quando nos referimos aos artigos dos representantes do setor empresarial estamos falando dos textos escritos por empresários, funcionários de empresas ou membros de entidades representativas do setor empresarial que possuem uma coluna periódica ou são convidados pela direção da Folha a expressar suas opiniões através de seus escritos. Dessa forma, excluímos de nosso objeto central de estudo os artigos de empresários, empresas e entidades patronais que foram publicados em espaços comprados com o objetivo de promover uma propaganda ou prestar esclarecimento sobre um fato de interesse específico a população, como também os colunistas desse jornal que, mesmo tendo uma identidade com o setor empresarial, não são empresários e muito menos pertençam a uma instituição ligada ao empresariado.

${ }^{4}$ SOUZA, Mário Luiz. "As Letras e o Consenso: burguesia, educação, imprensa e hegemonia". Tese (Doutorado em Educação) - Faculdade de Educação, Universidade Federal Fluminense, Niterói, ano 2010; orientada por Ronaldo Rosas
} 


\section{Trabalhonecessário}

ISSN: 1808 - 799X

ANO 12, № 19 - 2014

e na sociedade política ${ }^{5}$, de que o caminho para se combater essas históricas mazelas sociais seriam através da educação e que o empresariado teria um papel de destaque nesse processo. Em outras palavras, tendo como pressuposto teórico e metodológico a matriz marxista, em especial o pensamento de Antonio Gramsci, nesse artigo demonstramos que os artigos dos representantes do empresariado não são simples instrumentos de expressão, desprovidos de interesse de classe e de fração de classe. Ao contrário, são instrumentos políticos pelo qual seus autores, atuando como sujeitos políticos coletivos, buscam criar um consenso ativo, na sociedade civil e na sociedade política, tentando colocar suas idéias, suas propostas e suas demandas como elementos norteadores da agenda das políticas públicas sociais e dos movimentos sociais ligados a esse tema.

Assim sendo, esse trabalho caminha na linha de pensadores do campo trabalho e educação, como também daqueles que se dedicam ao estudo das políticas públicas educacionais, tendo a relação entre a educação e o setor empresarial como um dos focos de seus estudos. Essa temática vem sendo desenvolvida, dentro dos mais diferentes eixos, contribuindo para a construção do conhecimento sobre os princípios, formas e organização de propostas educacionais que são abraçadas pelo capital, no transcorrer da história do capitalismo. Nesse sentido, destacarei três autores que servem para exemplificar essa a importância dessa produção acadêmica e que tiveram influência sobre o trabalho que realizei no doutorado e que, em parte, está representada nesse artigo.

\footnotetext{
${ }^{5}$ Utilizando o conceito de Gramsci, a sociedade civil seria formada pelos "organismos chamados de privados", como sindicatos, ONGS, órgãos representativos de classes e associações, onde se exerce uma ação política consciente buscando determinados fins; enquanto a sociedade política seria o "Estado em sentido restrito", formado pelo aparelho burocrático, jurídico e policial-militar do Estado. Ver: GRAMSCI,1991, p:10 e 11.
} 


\section{Trabalhonecessário}

ISSN: 1808 - 799X

ANO 12, № 19 - 2014

O primeiro seria o caso do professor Gaudêncio Frigotto. Com uma ampla produção, Gaudêncio Frigotto destaca-se como um dos principais teóricos no campo trabalho e educação, publicando expressivos trabalhos que buscam debatera inserção da educação na lógica do capital, indo da discussão da Teoria do Capital Humano a Sociedade do Conhecimento, com o advento do neoliberalismo, da globalização e da maior inserção da ciência e da tecnologia no setor produtivo ${ }^{6}$. Entender a relação entre educação e o mundo do trabalho, principalmente a partir da década de 1980, através desse autor representa apreender o quanto a educação está inserida na luta de classes.

O segundo, ou melhor dizendo a segunda, seria a professora Lúcia Maria Wanderley Neves. Tendo como foco as políticas públicas no âmbito educacional, a professora Lúcia Neves também detém uma ampla produção acadêmica que fornece um embasamento teórico e metodológico para aqueles que se debruçam sobre a temática da educação dentro dos interesses e objetivos do capital. No caso desse artigo, destacamos o seu livro a Nova Pedagogia da Hegemonia ${ }^{7}$ no qual a autora defende que desde o final do século passado, a burguesia brasileira vem procurando legitimar entre os membros e representantes da classe trabalhadora, além de outros setores da sociedade civil, uma visão de mundo mais afeita aos seus interesses. Seria uma mudança de ação política de setores da burguesia que estariam caminhan-

\footnotetext{
${ }^{6}$ Entre os trabalhos desse autor destaco: FRIGOTTO, Gaudêncio. A Produtividade da Escola Improdutiva. 4º ed, São Paulo: Cortez Editora, 1993. FRIGOTTO, Gaudêncio. Educação e a Crise do Capitalismo Real. São Paulo: Cortez Editora, 1996. FRIGOTTO, Gaudêncio. Anos 1980 e 1990: a relação entre o estrutural e o conjuntural e as políticas de educação tecnológica e profissional. (In) CIAVATA, Maria e FRIGOTTO, Gaudêncio. FRIGOTTO, Gaudêncio. A Formação do Cidadão Produtivo: a cultura de mercado no ensino médio técnico. Brasília: Inep, 2006. Fundamentos Científicos e Técnicos da Relação Trabalho e Educação no Brasil de Hoje. In LIMA, Júlio C. França e NEVES, Lúcia M. Wanderley. Fundamentos da educação escolar do Brasil. Rio de Janeiro: Editora Fiocruz, 2006.

${ }^{7}$ Mais especificamente: NEVES, Lúcia Maria Wanderley e SANT'ANNA, Ronaldo. Gramsci, o Estado educador e a nova pedagogia da hegemonia. (In) NEVES, Lúcia Maria Wanderley (org.). $A$ Nova Pedagogia da Hegemonia: estratégia do capital para educar o consenso. São Paulo: Xamãizo05.
} 


\title{
Trabalhonecessário
}

\author{
ISSN: 1808 - 799X
}

\section{ANO 12, № 19 - 2014}

do no sentido de estabelecer uma hegemonia, em termos gramsciano, procurando criar um consenso ativo sobre seu projeto societário, nas mudanças que a sociedade brasileira passa a viver a partir da década de 1980. Esse, por exemplo, seria o caso da chamada responsabilidade social do empresariado. Nessa nova postura, a burguesia sairia de seu tradicional papel assistencialista para através de ações concretas, junto a organizações voltadas para trabalhos de cunho educacional e social, ter um papel fundamental no combate aos problemas sociais do país. E não seria apenas uma participação em termos de doações financeiras. Somado a isso, estaríamos diante de um empresário de novo tipo, que atuaria no direcionamento dos princípios e na gestão dessas organizações. Assim se configuraria uma nova forma de ação na tentativa de resolução dos problemas sociais, mas através de caminhos inseridos na ótica do capital. No trabalho que estou apresentando, através da análise dos representantes do empresariado, pude confirmar as colocações de Lúcia Neves, como o leitor poderá observar.

O terceiro é o trabalho do professor José Rodrigues, em especial seu livro 0 moderno Príncipe Industrial: o pensamento pedagógico da Confederação Nacional da Indústria ${ }^{8}$. Nesse estudo, abordando o pensamento sobre a educação defendido pela CNI (Confederação Nacional das Indústrias), o autor aponta que apesar do empresariado industrial há muito se dedicar ao tema da formação escolar, essa questão tomou uma maior centralidade a partir da década de 1980. Nesse período, o autor sustenta que o setor industrial, diante do acirramento da concorrência intercapitalista, reforçou seu discurso sobre o papel da educação, como fator fundamental para a competitividade das empresas, realização do trabalhador, melhoria social e desenvolvimento da nação. Mas como fruto de uma disputa de classe, não seria qualquer educação, acima disso seria uma educação inserida na

\footnotetext{
${ }^{8}$ RODRIGUES, José. O moderno Príncipe Industrial: o pensamento pedagógico da Confederação Nacional da Indústria. Campinas. São Paulo: Autores Associados, 1998.
} 


\section{Trabalhonecessário}

ISSN: 1808 - 799X

\section{ANO 12, № 19 - 2014}

lógica do capital. Na pesquisa que realizamos para o doutorado, da qual parte consta nesse artigo, verificamos que o setor industrial não só manteve como aprofundou as posições apontadas por José Rodrigues.

Antes de começarmos a debater os dados e análises resultantes do trabalho empírico com nossas fontes, cabe traçar algumas linhas para explicar nossa escolha para dedicarmos uma maior atenção aos artigos publicados no jornal paulista, uma vez que tal opção metodológica não foi aleatória.

No levantamento empírico, sobre os dois jornais, identificamos um conjunto de 750 textos escritos por representantes do empresariado. Porém a maioria desses artigos foi publicado na Folha de São Paulo e não no jornal O Globo. Enquanto nesse último encontramos 25 artigos, com 11 havendo referências a educação, no primeiro há 725, com 244 contendo referências à educação. Além disso, a escolha pelo jornal paulista, permitiu a comparação dos resultados da pesquisa do doutorado, que cobriu o período de 1999-2006, com os da pesquisa realizada para minha dissertação no qual também trabalhei com os artigos do empresariado com relação à educação, publicados no jornal Folha de São Paulo, no período $1994-1998^{9}$. Isso possibilitou identificar continuidades e mudanças na postura dos representantes do empresariado, principalmente no caso do setor industrial. Em resumo, esse conjunto de aspectos, favoreceu nossa predileção pela utilização dos artigos publicados na Folha, na condução de nossa abordagem.

\section{A FALA DO SETOR FINANCEIRO}

Os dados levantados pelo nosso trabalho empírico, indicou que houve poucos artigos dos representantes do setor financeiro dedicados ao debate sobre os problemas sociais brasileiros, como indica o quadro abaixo:

\footnotetext{
9 SOUZA, Mário Luiz. "Imprensa e Hegemonia: como a Folha de São de Paulo trabalhou a reforma educacional do primeiro governo FHC". Dissertação (Mestrado em Educação) - Faculdade de Educação, Universidade Federal Fluminense, Niterói, ano 2002; orientada por Lúcia Neves.
} 


\section{Trabalhonecessário}

ISSN: 1808 - 799X

ANO 12, № 19 - 2014

Quadro I - Artigos do setor financeiro com presença do tema educação ${ }^{10}$
\begin{tabular}{|c|c|c|}
\hline Temas & Total de Artigos & $\begin{array}{c}\text { Artigos } \\
\text { Com a Presença } \\
\text { da Educação }\end{array}$ \\
$\qquad \begin{array}{c}\text { Crescimento } \\
\text { Econômico }\end{array}$ & 39 & 13 \\
\hline $\begin{array}{c}\text { Problemas } \\
\text { Sociais }\end{array}$ & 2 & 2 \\
\hline Emprego & 0 & 0 \\
\hline Total & $\mathbf{4 1}$ & $\mathbf{1 5}$ \\
\hline
\end{tabular}

Por outro lado, uma vista mais criteriosa sobre o quadro acima demonstra que nos dois artigos sobre os problemas sociais no país, assinado por representantes desse setor, a educação aparece como um instrumento para que essa chaga seja superada.

No único artigo em que Roberto Luis Troster $^{11}$ referente aos problemas sociais, há uma defesa de um projeto de sociabilidade no qual a resolução do histórico problema da concentração de renda no país se resolve com o estabelecimento de um crescimento econômico e com a implantação de um sistema educacional que possibilite ao trabalhador participar do mundo produtivo e da riqueza social. Uma sociabilidade na qual as noções de inclusão e cidadania, inseridas na lógica capitalista, têm como marca as condições de consumo do indivíduo frente aos produtos ofertados pelo mercado, no caso, o financeiro.

Noutro artigo do setor financeiro abordando os problemas sociais e a educação, há uma abordagem totalmente diferente da que ocorre no texto citado

\footnotetext{
${ }^{10}$ Com relação a $O$ Globo há 14 artigos, com quatro tendo menção sobre educação: crescimento econômico, 10 artigos, com apenas dois abordando a questão da educação; problemas sociais com quatro artigos, sendo dois trazendo informações sobre educação e a mesma abordagem dominante nos artigos publicados no jornal Folha de São Paulo; e nenhum inserido na categoria emprego.

${ }^{11}$ Doutor pela Faculdade de Economia e Administração da USP. Foi economista-chefe da Febraban (Federação Brasileira dos Bancos) de 2001 a 2006.
} 


\section{Trabalhonecessário}

ISSN: 1808 - 799X

ANO 12, № 19 - 2014

anteriormente. No artigo em que Antonio Jacinto Matias (MATIS, 2006, p.3), vice presidente do Banco Itaú e presidente da Fundação Itaú Social, faz um relato do "Seminário Nacional Tecendo Redes para Educação Integral e apresenta algumas propostas visando a melhoria do nível da educação brasileira para que também haja a melhoria das questões sociais. Sustentando que os resultados insatisfatórios da Prova Brasil revelam a necessidade premente de se estabelecer mudanças na educação brasileira, Matias aponta que mesmo que os debates no Seminário tenham indicado que não há uma definição acerca do melhor modelo de educação integral para o país, foi unânime a conclusão de que a melhoria da educação brasileira passa pelo envolvimento de toda sociedade, envolvendo Estado, escolas, educadores, ONGs, família e iniciativa privada:

[...] lideranças comprometidas com a causa da educação procuram mobilizar a sociedade em amplo movimento que envolva a todos, transformando esse tema na grande prioridade do Brasil.

Abrir o debate para toda a sociedade é ponto de partida para toda transformação social [...].

Isso mostra que cada comunidade pode fazer sua própria estratégia de adoção do sistema de acordo com sua realidade. A iniciativa privada, por exemplo, pode disponibilizar sua capacidade de gestão e seus investimentos em prol da articulação para fortalecimento do processo. As ONGs podem se responsabilizar por atividades complementares. Os pais podem se comprometer com uma participação mais ativa. $E$ as secretarias de educação podem propor parcerias com as pastas de Planejamento e Desenvolvimento Social (MATIS, 2006, p.3).

Nessa mesma linha temos, temos num artigo publicado no $O$ Globo, por Pedro Moreira Salles (SALLES, 2000, p.7), presidente administrativo do conselho de Administração do Unibanco e conselheiro do Programa Comunidade Solidária, a defesa da ação efetiva da participação do empresariado, na forma da responsabilidade social, como um fator decisivo para o combate as questões sociais que rasgam o país. Na busca da legitimação dessa posição, aponta que tornou-se imprescindível para a questão social a associação do Estado com o setor 


\section{Trabalhonecessário}

ISSN: 1808 - 799X

ANO 12, № 19 - 2014

privado, tendo as universidades públicas como foco de atuação para utilizar os alunos nesse processo, sob a gestão do terceiro setor.

\section{A VISÃO DO SETOR COMERCIAL E DE SERVIÇOS}

Como no caso do setor financeiro, o trabalho empírico indicou poucos artigos dedicados ao debate sobre a questão social:

Quadro II - Artigos do setor comercial e de serviços com presença do tema educação ${ }^{12}$

\begin{tabular}{|l|c|c|}
\hline Categorias & $\begin{array}{c}\text { Total de } \\
\text { Artigos }\end{array}$ & $\begin{array}{c}\text { Artigos } \\
\text { Com a } \\
\text { Presença } \\
\text { da Educação }\end{array}$ \\
\hline $\begin{array}{l}\text { Crescimento } \\
\text { Econômico }\end{array}$ & 52 & 12 \\
\hline $\begin{array}{l}\text { Problemas } \\
\text { Sociais }\end{array}$ & 2 & 2 \\
\hline Emprego & 3 & 1 \\
\hline Total & $\mathbf{5 7}$ & $\mathbf{1 5}$ \\
\hline
\end{tabular}

Fontes - jornal Folha de São Paulo (1999-2006)

Num artigo publicado em 2003, Abram Szajman ${ }^{13}$, apontando que a gama de problemas sociais que os jovens das comunidades carentes passam reside na pífia presença do Estado nessas áreas, sobretudo na falta da oferta de uma educação pública de qualidade, parabeniza os setores da sociedade civil que estão abraçando a causa da responsabilidade social, em especial o empresariado:

[...] Os empresários mais conscientes também têm dado a sua contribuição, por meio de entidades como Sesc, Senac, Sesi e Senai, seja com programas voltados à formação integral dos jovens, seja com

\footnotetext{
${ }^{12}$ Com relação a $O$ Globo há um total de 20 artigos, com apenas três tendo menção sobre educação: crescimento econômico, 15 artigos, com nenhum abordando a questão da educação; problemas sociais com quatro artigos, sendo dois trazendo informações sobre educação; e um inserido na categoria emprego, sendo que nesse a educação também consta entre as temáticas debatidas.

${ }^{13}$ Presidente da Fecomercio-SP (Federação do Comércio do Estado de São Paulo) e dos conselhos regionais do Sesc e do Senac.
} 


\section{Trabalhonecessário}

ISSN: 1808 - 799X

ANO 12, № 19 - 2014

programas de qualificação profissional e colocação no mercado de trabalho.[...] (SZAJMAN, 2003, p.3).

Contudo, aponta que isso não exclui a presença do Estado:

Sabemos que as soluções urgentes para a grave situação de
vulnerabilidade a que está exposto o jovem brasileiro, principalmente da
periferia, devem vir da formulação de políticas públicas específicas para
essa faixa etária, como educação para o trabalho, formação de
cooperativas de trabalho, desarmamento, lazer socioeducativo e cultural.
Mas onde estão essas políticas públicas? (SZAJMAN, 2003, p.3) (grifos
nossos)

Temos então, uma formulação do embate aos problemas sociais que marcam o cotidiano dos jovens das comunidades carentes, delineados dentro de uma concepção no qual se busca incorporá-los aos padrões de sociabilidade referente à cidadania e a resolução dos seus problemas, sob a lógica do capital, centrada no acesso ao serviço público e na inserção desses jovens no mercado de trabalho. Nesse projeto, a educação ocupa um lugar de destaque no discurso do presidente da Fecomercio. Mas, como se deduz na leitura do texto, não estamos falando de qualquer modelo de educação e sim de uma educação escolar cuja diretriz tenha como fundamento uma educação para o trabalho, ou seja, para a lógica do mercado.

Em outro artigo, Szajman (2006), defendendo a ação social realizada pelo Sesc e o Senac, volta a destacar a ação empresarial no combate aos problemas sociais e a relação da educação para o trabalho como instrumento de via desse processo:

[...] o sistema tributário, reduzido ao debate econômico, só faz as ações desenvolvidas há anos pelo Sesc e pelo Senac, de assistência social, de educação social, de atividades comunitárias, de diferente ocupação do tempo livre e de democratização do acesso à cultura e à educação para o trabalho e para a vida harmônica em sociedade. (grifos nossos) (SZAJMAN, 2006, p.3) 


\section{Trabalhonecessário}

ISSN: 1808 - 799X

ANO 12, № 19 - 2014

Sempre buscando legitimar o papel do Sesc e do Senac, Szajman aponta que há tempos o empresariado do comércio e serviços vem praticando uma ação social vigorosa na sociedade, tendo como meta a transformação e a justiça social, muito antes da chamada função social da empresa tornar-se uma realidade aceita em diversos segmentos da sociedade. Sob essa lógica, fecha o seu artigo citando que o poder público deve evitar ações que comprometam essas entidades na sua ação social, principalmente na esfera educacional pois isso: "[...] só fará aumentar ainda mais a desigualdade e os graves problemas de toda ordem em nosso país. Fato inaceitável no limiar do século 21." (SZAJMAN, 2006, p.3).

\section{O PENSAMENTO DO CAPITAL INDUSTRIAL SOBRE OS PROBLEMAS SOCIAIS E A EDUCAÇÃO}

Comparando o período coberto pela nossa pesquisa para o doutorado (1999-2006) com a nossa pesquisa para o mestrado (1994-1998), verificamos que há um crescimento constante no número de artigos publicados pelos representantes do setor industrial, nos quais a educação aparece, como demonstra o quadro abaixo:

Quadro III - Quantidade de artigos em que aparece o tema educação por período de governo relacionado a uma determinada temática ${ }^{14}$

\begin{tabular}{|c|c|c|c|}
\hline Temas & $\begin{array}{c}\text { Artigos no Período } \\
\text { do Primeiro } \\
\text { Governo FHC }\end{array}$ & $\begin{array}{c}\text { Artigos no } \\
\text { Segundo Governo } \\
\text { FHC }\end{array}$ & $\begin{array}{c}\text { Artigos no } \\
\text { Governo Lula }\end{array}$ \\
\hline $\begin{array}{c}\text { Crescimento } \\
\text { Econômico }\end{array}$ & 33 & 41 & 61 \\
\hline $\begin{array}{c}\text { Problemas } \\
\text { Sociais }\end{array}$ & 6 & 36 & 32 \\
\hline Total & $\mathbf{4 5}$ & $\mathbf{8 2}$ & $\mathbf{1 0 3}$ \\
\hline
\end{tabular}

Fontes - jornal Folha de São Paulo (1999-2006)

14 Com relação a O Globo temos 14 artigos, contendo menções sobre educação: crescimento econômico, 12 artigos, com três abordando a questão da educação; problemas sociais com dois artigos, sendo um trazendo informações sobre educação; e nenhum inserido na categoria emprego. 


\section{Trabalhonecessário}

ISSN: 1808 - 799X

ANO 12, № $19-2014$

Porém esses dados demonstram que além do aspecto quantitativo há uma mudança qualitativa no discurso do empresariado industrial sobre a educação. Apesar da manutenção do predomínio da inserção da educação no discurso do empresariado industrial na lógica do crescimento econômico, há um sensível crescimento da predileção dos representantes dessa fração da classe dominante entre a educação e a questão das mazelas sociais. Somado a isso, essa mudança no discurso toma um maior vulto quanto atentamos para outro dado oriundo da pesquisa empírica, registrada no quadro abaixo:

Quadro IV - Quantidade de artigos em que aparece a educação

\begin{tabular}{|l|c|c|}
\hline Temas & $\begin{array}{c}\text { Número } \\
\text { Total } \\
\text { de Artigos }\end{array}$ & $\begin{array}{c}\text { Artigos em } \\
\text { que aparece } \\
\text { a educação }\end{array}$ \\
\hline Crescimento Econômico & 456 & 102 \\
\hline Problemas Sociais & 88 & 68 \\
\hline Emprego & 46 & 15 \\
\hline Total & $\mathbf{5 9 0}$ & $\mathbf{1 8 5}$ \\
\hline
\end{tabular}

Fontes - jornal Folha de São Paulo (1999-2006)

Enquanto o enfoque da educação aparece bem abaixo da metade dos artigos cuja temática passa pela questão do crescimento econômico, sua presença surge numa parcela substancial dos textos referentes aos problemas sociais. Diante dessa constatação, cremos que se configura um processo no qual a inserção da educação como fator imprescindível para a construção de uma nova sociabilidade passa a ter um papel relevante, na estruturação do discurso educacional do setor industrial.

$\mathrm{Na}$ comparação dos artigos dos representantes do setor industrial pesquisados para a dissertação de mestrado (publicados entre 1995-1998) com 


\section{Trabalhonecessário}

ISSN: 1808 - 799X

ANO 12, № 19 - 2014

àqueles que serviram como fontes para a tese do doutorado (publicados entre 199-2006), foi constatado uma diferença significativa. Nesses últimos passou a vigorar uma proposta que nos primeiros era algo embrionário: a defesa da ativa participação do terceiro setor, de ONGs e, notadamente, do empresariado, na luta pelas modificações das precárias condições sociais que ceifam a sociedade brasileira.

Para se ter uma ideia desse processo, nos 68 artigos sobre os problemas sociais em que aparece o tema educação, em 39 deles a participação do empresariado surge como fundamental, seja através de parcerias com o poder público ou por meio da responsabilidade social. Por sinal, esse discurso é extremamente orgânico, uma vez que busca o convencimento sobre essa proposta, não apenas na sociedade civil e no aparelho do Estado, mas também entre o próprio empresariado. Em muitos desses artigos, busca-se atrair o empresariado brasileiro a ter uma nova postura diante dos problemas sociais, requisitando um maior protagonismo dessa classe social, dentro da lógica que iremos abordar. Em outras palavras, os artigos contém a busca do convencimento de um novo direcionamento moral e intelectual das ações para debelar a questão social, dentro de parâmetros definidos sob a ótica do capital, no qual a própria classe burguesa também é alvo desse processo.

Nessa ação política, o trabalho empírico indicou a Viviane Senna ${ }^{15}$ como uma das principais intelectuais orgânicas do setor industrial na abordagem das questões sociais. Sempre apontando que não se pode mais pensar em desenvolvimento econômico apartado de desenvolvimento social, essa intelectual orgânica defende que, apesar da importância de toda sociedade, o papel central na luta pela melhoria das condições sociais do povo brasileiro é co-responsabilidade

\footnotetext{
${ }^{15}$ Presidente do Instituto Ayrton Senna e faz parte do grupo Todos Pela Educação.
} 


\section{Trabalhonecessário}

ISSN: 1808 - 799X

ANO 12, № 19 - 2014

dos três segmentos da vida pública nacional: "[...] o primeiro setor, público com fins públicos que é o governo; o segundo setor, privado com fins privados, que é o universo empresarial; e o terceiro setor, privado com fins públicos, construído por organizações sem fins lucrativos" (SENNA, 2000, p.3). A ação desses três segmentos na implementação de ações socioeducativas, nos artigos dessa representante do setor industrial, é posto como fator imperativo para o combate dos problemas sociais, tendo como foco a: "[...] preparação para a cidadania e para o mundo do trabalho" (SENNA, 2000, p.3).

Noutro artigo (SENNA, 2000, p.3), debatendo os dados do Relatório sobre - Desenvolvimento Humano do Programa das Nações Unidas Para 0 Desenvolvimento - o PNUD, Viviane Senna afirma que o Brasil está longe de um mínimo de equilíbrio entre transformação produtiva e equidade social e reafirma a proposta para superar tal situação através da ação orgânica dos três setores citados:

De fato, em 500 anos de história, acumulamos um passivo social cujo resgate só poderá ser empreendido pela convergência e complementaridade de esforços das políticas públicas, do mundo empresarial e das organizações sem fins lucrativos, que integram 0 chamado terceiro setor.

Diante desse quadro, impõe-se, de forma inarredável e urgente, a adoção de uma ética de co-responsabilidade entre os três grandes setores da vida nacional. Cumpre ao Estado não abrir mão de seus fins universais e se empenhar na construção de políticas públicas efetivamente redistributivas e autopromotoras. Ao mundo empresarial, cabe identificar aspectos relevantes do desenvolvimento social brasileiro e atuar de forma complementar ao poder público, no sentido do aumento e da melhoria das ações no foco eleito.

Por fim, às organizações do terceiro setor cabe, com sua sensibilidade, espírito de luta e criatividade pessoal, institucional e comunitária, contribuir para a expansão dos limites do possível, através da produção de ideia e iniciativas que se mostrem capazes de promover a alteração das ações do governo e das empresas, no que diz respeito ao bem comum.

Essa nova ótica e essa nova ética precisam ser instaladas na consciência social do nosso tempo.[...] (SENNA, 2002, p.3) (grifos nossos) 


\section{Trabalhonecessário}

ISSN: 1808 - 799X

ANO 12, № 19 - 2014

Temos assim, um terceiro setor, como o Instituto Ayrton Senna, com um grande papel na relação descrita acima, uma vez que vai contribuir através de ideia e iniciativas que se mostrem capazes de promover a alteração das ações do governo e das empresas, ou seja, terá um papel influente na direção moral e intelectual das ações feitas pelo governo. Seria a abertura de mais espaço no aparelho de Estado, para a ação direta do setor empresarial na condução de políticas públicas e de outras propostas do setor industrial, ao mesmo tempo em que reforça no tecido social a lógica da nova sociabilidade de que os aspectos sociais só podem ser resolvidos por ações pontuais, e não mais universais, na qual o papel da participação do empresário e de outros agentes sociais é imprescindível, como atesta esse trecho do artigo de Ruy Martins Alfendenter Silva ${ }^{16}$ :

Em países emergentes, como o Brasil, são mais graves e visíveis problemas como a fome, o abandono da infância e da juventude, analfabetismo, saúde deficitária e violência.

Em contrapartida à incapacidade do Estado, desenvolve-se de forma muito fértil a cidadania empresarial e o voluntariado. Em todo o mundo, no universo do chamado terceiro setor, pessoas de boa vontade, empresas, fundações, institutos privados e ONGs tornaram-se atores vitais na promoção social. Atuando de forma complementar ao Estado, realizam eficazes programas de saúde, educação, cultura, esportes, reintegração social e iniciação profissional. Essas organizações estão mais próximas da realidade das ruas e dos problemas da comunidade, focando de maneira mais precisa as questões a serem sanadas. Além disso, têm o paradigma empresarial do compromisso com resultados.

O Estado, além da carência de recursos em relação ao tamanho da demanda social, continua patinando em equívocos do passado, mantendo programas superpostos e, o que é pior, nem sempre adequados à realidade nacional e/ou às peculiaridades de uma região ou cidade.

[...] A mira na realidade é decisiva. Assim, o Fome Zero, a despeito de suas excelentes intenções, talvez ainda esteja dissociado de muitas realidades regionais e de estratégias e logísticas eficientes. De nada adianta propor soluções distantes da realidade. É preciso dar de comer a quem tem fome, educação aos incautos, dar remédio aos doentes, casa aos desabrigados. A palavra é foco, conforme demonstram as lições da

${ }^{16}$ Então diretor geral do Instituto Roberto Simonsen da Fiesp/Ciesp. 


\title{
Trabalhonecessário
}

ISSN: 1808 - 799X

ANO 12, № 19 - 2014

dialética materialista e de episódios como o da pobre vaca de Sarandi (SILVA, 2002, p.3). (grifos nossos)

Outro importante representante do setor industrial que se destacou nesse discurso, foi o empresário Benjamin Steinbruch. Num artigo (STEINBRUCH, 1999, p.2), em que cria o personagem nosso Zé, parodiano o fato do então secretário geral da ONU, Kofi Annam, ter escolhido um bebê sérvio, Adnan Nevil, para simbolizar, no dia das crianças, a precária situação que diversas crianças vivem no mundo globalizado, esse industrial destaca a necessidade da atuação de toda a sociedade brasileira e do Estado para que haja a resolução dos problemas dos nossos "Zés":

\begin{abstract}
A cidadania aos poucos está tomando consciência de que o resgate da divida social dos brasileiros não se poderá fazer apenas por meio de medidas governamentais ou golpes de marketing. Ela precisará resultar de uma ação de toda a sociedade, com as responsabilidades divididas entre as autoridades do Estado e as representações legitimas da produção e do trabalho, em um esforço que deverá engajar todos os brasileiros, suas famílias, seus negócios, suas representações associativas ou políticas (STEINBRUCH, 1999a, p.2).
\end{abstract}

Assim sendo, Benjamin Steinbruch caminha na proposta da linha de responsabilidade social, incorporando outros setores da sociedade, mas deixando claro o quanto isso também engloba a ação do empresariado, na resolução da dívida social.

Noutro artigo, também publicado no ano de 1999, esse industrial volta de forma mais incisiva a questão da inserção do empresariado na resolução dos problemas sociais, defendendo que se alastra uma nova mentalidade em que ter uma empresa com destaque na esfera econômica não mais se reduz ao acúmulo de lucro registrado no balancete do final de ano. Acima disso, ser uma grande empresa é associar o ganho financeiro com o ganho de ter propiciado as condições para superação da dívida social: 


\title{
Trabalhonecessário
}

ISSN: 1808 - 799X

ANO 12, № 19 - 2014

\begin{abstract}
Graças a esse sentimento de nova cidadania já se nota um novo movimento serio e crescente, que busca definir uma "empresa cidadã", cujas ações e investimentos precisam estar lastreados em padrões éticos e valores sociais. A nova empresa brasileira não pode mais viver "low profile" e, muito menos, no "no profile" [deve promover ou participar] de ações sociais relevantes. (STEINBRUCH, 1999b, p.2).
\end{abstract}

Esse discurso, de uma forma ou de outra, no conjunto de oito artigos desse empresário, publicados no transcorrer do segundo governo $\mathrm{FHC}$, no qual a educação aparece como instrumento para se combater os problemas sociais brasileiros, há uma defesa do tripé empresariado, Estado e outros segmentos da sociedade, como fator imperativo para efetivação desse processo. Contudo, Benjamin Steinbruch não reduz a constituição e ação desse tripé como único fator para a mudança do quadro social. Para esse intelectual orgânico da burguesia industrial, essa fórmula só dará o resultado esperado se tiver associado a um projeto de desenvolvimento do país, no qual o crescimento econômico, alicerçado no setor produtivo, também tenha como um dos seus principais pressupostos o crescimento das condições socioeconômicas da população, não como um objetivo futuro e sim como elemento constitutivo do presente:

\begin{abstract}
Já estamos longe do planejamento frio,lastreado em projetos desligados de parâmetros e objetivos sociais, como única forma de gerar riquezas, para depois, distribuí-las pela sociedade. Os caminhos que o Brasil adotou foram outros e neles se busca uma sintonia, um paralelismo, entre objetivos sociais e os meramente econômico, na certeza de que esses caminhos não são excludentes ou incompatíveis. Ao contrário, a sua adoção simultânea e criteriosa facilita as conquistas e permite a incorporação da sociedade e de seus cidadãos nas grandes lutas necessárias para que se aumente a produção, se estimulem investimentos, se prepare o Brasil para enfrentar, com segurança, os vendavais do capitalismo virtual e os desafios da competitividade e da eficiência, que serão as marcas da nova economia brasileira (STEINBRUCH, 1999c, p.2).
\end{abstract}

Então, como vemos, há nessa citação uma nova proposta para substituir as formas mais correntes de embate da dívida social pelas mais diferentes vertentes. 


\section{Trabalhonecessário}

ISSN: 1808 - 799X

ANO 12, № 19 - 2014

Primeiro assumindo que isso é fruto da realidade concreta do país e que não pode mais ser postergada. E segundo, talvez o âmago da questão, a articulação entre o enfrentamento da divida social e a constituição de um projeto econômico consistente para o país enveredar pela competitividade do mundo globalizado. Todavia, não é um nexo em que apenas o econômico responde às necessidades do social, acima disso há uma relação orgânica entre as duas esferas se retroalimentando e formando um verdadeiro processo de desenvolvimento. Nesse caso, não apenas os despossuídos seriam os beneficiados, mas a própria burguesia, que teria uma força de trabalho com condições físicas e cognitivas para mover seus negócios dentro das novas determinações reinantes na competitividade do mundo capitalista. Não é à toa que Benjamin Steinbruch, nesse mesmo texto, aponta que deve haver uma mudança ético-política no tratamento reservado à questão social na sociedade brasileira, principalmente entre seus pares:

\footnotetext{
A hora é de reconhecer as nossas falhas, admitir a dívida social que se criou em décadas de imprevidência e desmantelo e fazemos uma grande corrente, o governo, as empresas, os trabalhadores, para que juntos enfrentemos, aqui dentro, os promotores do atraso e, lá fora, os que não querem abrir espaço para a chegada das nações emergentes, que não brilham no novo século que se aproxima (STEINBRUCH, 1999c, p.2).
}

Em outro texto, Benjamin Steinbruch reforça essa visão sobre a forma do enfrentamento da dívida social, estabelecendo a importância do crescimento econômico e reforçando seu discurso de mudança de mentalidade do empresariado:

[...] Todos os caminhos do resgate à pobreza e da eliminação da miséria passam pelo crescimento econômico. (...) Pelo fortalecimento do setor privado (...). Assim também pelos esforços para elevação dos níveis de educação, da saúde, de treinamento profissional".

(...) Também estão ligados a esses esforços [combater a pobreza através da articulação crescimento econômico e pagamento da divida social], a uma consciência social do empresariado e de uma certeza de que não haverá a- 


\title{
Trabalhonecessário
}

ISSN: 1808 - 799X

ANO 12, № $19-2014$

vanços duradouros e confiáveis se não combatemos com medidas práticas as desigualdades regionais e as divergências de renda que afastam, de forma absurda, as receitas dos mais afortunados das classe média, dos profissionais autônomos e dos trabalhadores de quase todos os segmentos da economia (STEINBRUCH, 1999d, p.2).

Como tal, vemos que se estabelece uma forma de ação política, que estrutura uma articulação entre o econômico e a superação dos entraves sociais, subsumindo a lógica do combate a exclusão social aos parâmetros definidos por uma ação ideológica moldado pela ótica do capital. Formam-se, assim, as bases para uma nova sociabilidade, em que o desenvolvimento econômico é apresentado como o fator operante para se ter uma sociedade mais justa e igualitária. Mas um desenvolvimento econômico que teria nesse "empresário de novo tipo" um papel de destaque na transformação do ganho capitalista em ganho real para toda sociedade brasileira. Tanto que nesse mesmo artigo, Benjamin Steinbruch busca difundir uma visão especial do lucro, objetivando retirar seu caráter meramente patrimonial e mercantil, atribuindo-Ihe uma dimensão e legitimidade social:

\begin{abstract}
O lucro é o fermento da produção. Temos que ter para dar certo uma boa receita econômica, uma boa mão empresarial e lucro para crescer com o país. O lucro é o resultado e a causa de investimentos que trazem novos empregos, bem-estar social, desenvolvimento e progresso. Não temos de ter vergonha de ter lucro. Pelo contrario quanto mais lucro mais impostos. (..) Que bom seria se tivéssemos uma economia forte e crescente, em que todos tivessem lucros para serem reinvestidos, em uma onda permanente, com isso, mais emprego e mais produção. (..) $\mathrm{E}$ como esse é e deve ser o nosso caminho para reduzir a pobreza e erradicar a miséria. (STEINBRUCH, 1999d, p.2)
\end{abstract}

Essa linha de abordagem, unindo educação, crescimento econômico e atuação do empresariado e outros segmentos da sociedade, junto ao Estado, no embate dos problemas sociais, também há nos artigos do empresário Jorge Gerdau Johannpeter ${ }^{17}$. No artigo em que apresenta o objetivo do movimento

\footnotetext{
17 Presidente do Conselho de Administração do Grupo Gerdau, um dos principais grupos siderúrgicos do país, presidente fundador do Movimento Brasil Competitivo (MBC), coordenador da
} 


\title{
Trabalhonecessário
}

ISSN: 1808 - 799X

ANO 12, № 19 - 2014

Compromisso de Todos Pela Educação, essa lógica se apresenta de forma orgânica, como demonstra o trecho abaixo:

\begin{abstract}
APROXIMADAMENTE seis anos. Esse é o tempo médio de escolaridade dos brasileiros, o que demonstra a grande fragilidade do país na construção de um futuro com menores desigualdades sociais. Por isso, muitas empresas chegam a investir, por ano, até cem horas na capacitação de seus funcionários, o que significa mais de duas semanas inteiras. O retorno é concreto: pessoas com desempenho superior são mais produtivas, mais felizes e inovam em processos e produtos, o que se traduz em melhores resultados para as empresas. Mas, quando se trata de analisar a atuação cidadã da elite empresarial, política, acadêmica e sindical, os resultados ainda não são satisfatórios. Falta indignação por parte da elite. Ela tem a obrigação de construir um país melhor e mais organizado institucionalmente, com menos corrupção e mais capital social, possibilitando a construção da igualdade de oportunidades por meio da educação. Para isso, é preciso formar um forte capital social e reforçar a capacidade competitiva e inovadora do país. O capital social ajuda a manter a coesão social, o que resulta em uma sociedade mais aberta e democrática. Reflete o grau de confiança entre os atores da sociedade e sua capacidade de estabelecer relações de cooperação em torno de interesses comuns. As comunidades não se tornaram cívicas por serem ricas. A história mostra o oposto: enriqueceram por serem cívicas. A construção do capital social, da competitividade e da inovação em uma nação somente se efetiva quando fundamentada em processos de excelência na gestão pública e privada.
\end{abstract}

[...] O país não cresce significativamente, entre outros fatores, porque não tem uma população com educação de qualidade. É preciso que a sociedade compartilhe cada vez mais as responsabilidades. Mais importante do que a doação de recursos é a transferência de tecnologias de gestão presentes nas empresas, que permitem fazer mais com menos, de forma mais eficiente, tornando as instituições autosustentáveis. Afinal, o futuro do Brasil está na produtividade de toda a sociedade-não basta que apenas as empresas sejam produtivas. (GERDAU, 2006, p.2) (grifos nossos)

Vemos, portanto, a educação como instrumento pelo qual se efetivará as condições concretas para o enfrentamento das condições sociais da população, mas não como algo que basta o aumento de sua qualidade para tal fato se concretize. Esse processo educação, para dar o resultado esperado na esfera so-

Ação Empresarial, faz parte da diretoria do ledi (Instituto de Estudos para o Desenvolvimento Industrial) e do comitê executivo do grupo Todos Pela Educação. 


\section{Trabalhonecessário}

ISSN: 1808 - 799X

ANO 12, № $19-2014$

cial, deve estar atrelado a um projeto de crescimento econômico, no qual também será um elemento primordial porque possibilitará as condições objetivas e subjetivas de uma força de trabalho para o aumento da produtividade das empresas. Então a educação interliga dos fatores que se retroalimentam, o crescimento econômico no tocante a formação de força de trabalho e o caminho para resolução dos problemas sociais através da construção da igualdade de oportunidades por meio da educação. Por isso, que não é qualquer educação, que Jorge Gerdau defende, pelo contrário é uma formação escolar subsumida a lógica do capital. Não é à toa, que esse empresário não poupa crítica aos seus próprios pares, ao reforçar o discurso da responsabilidade social do empresariado. Parece que quer alertá-los que estão em condições de inserir o movimento de combate aos problemas sociais na lógica da reprodução social capitalista, como único vetor para se obter a coesão social e o caminho para $o$ indivíduo fruir os benefícios do crescimento econômico.

Nessa mesma linha, num outro artigo (GERDAU, 2006b, p.2), Jorge Gerdau, após sustentar que o Estado não tem mais condições de arcar sozinho com a resolução do problema social, em virtude da ineficiência da gestão pública e da falta de recursos, reafirma a questão da participação do empresariado na resolução dos problemas sociais, através da responsabilidade social e do voluntariado, pontuando as práticas capitalistas como fator operante na condução do combate a questão social:

Nas empresas, existem diferentes tipos de atuação na área de responsabilidade social. Algumas são meras doadoras de recursos e ignoram a eficiência de seus investimentos; outras são financiadorasdão o dinheiro e fiscalizam sua aplicação; finalmente, outras têm atitudes empreendedoras, ao participar da construção de melhores entidades sociais por meio da sua atividade voluntária e a de seus funcionários.

A decisão das empresas de assumir atitude empreendedora resulta da mobilização de sua principal liderança, movida por convicções espirituais, emocionais ou materiais. Independentemente dos motivos, a atividade voluntária do setor privado significa enorme ganho para a sociedade devido 


\title{
Trabalhonecessário
}

ISSN: 1808 - 799X

\begin{abstract}
ANO 12, № 19 - 2014
à transferência de suas práticas de gestão, determinantes para 0 sucesso de qualquer empreendimento. $O$ voluntariado permite obter melhor eficiência econômica e aprimorar o comportamento humano. Faz com que as instituições sociais se tornem capazes de administrar melhor suas atividades e de mobilizar a comunidade para as suas causas com mais eficiência. (GERDAU, 2006b, p.2) (grifos nossos)
\end{abstract}

Oded Gravew foi outra importante referência na construção do discurso do setor empresarial industrial na abordagem da educação na resolução dos problemas sociais do país. Conhecido pela defesa da atuação direta do empresariado na luta pelas melhorias dos problemas sociais do país, através de ações e parcerias com órgãos governamentais, pautado pela lógica da responsabilidade social das empresas e da cidadania empresarial, esse intelectual orgânico foi responsável por 18 dos 68 artigos dos representantes do setor industrial abordando a temática dos problemas sociais no âmbito da lógica exposta. Apesar dessa importância, optamos por não desenvolvermos nossas observações através de abordagem presente nos artigos de Gradew, uma vez que a ligação que teve com o PT e com movimentos sociais, chegando a ser um dos idealizadores do Fórum Social Mundial, e de algumas posturas assumidas por esse industrial ${ }^{18}$, poderia ser interpretado como as teses de um grupo de industriais que não reflete a posição de setores influentes dessa fração da burguesia brasileira. No entanto, pelo que mostramos sobre o pensamento difundido pelos outros intelectuais orgânicos do setor industrial, vemos que há em suas teses, todo um conjunto de análises e propostas, que apesar de algumas divergências, no todo reforçam o projeto dos importantes setores do empresariado industrial com relação ao embate frente à questão social e a subsunção da educação nesse processo.

\footnotetext{
18 Apenas para ilustrar essa nossa posição, podemos citar alguns fatos que não foram interpretados como unanimidade entre os industriais: apoio ao plebiscito da CNBB em relação a dívida externa em GRAJEU, Oded. Converter a dívida externa em programas sociais. Folha de São Paulo. São Paulo, 29 set. 20, Tendências e Debates, Caderno Brasil, p.3; apoio a candidatura Lula em Id. Lula Candidato. Folha de São Paulo. São Paulo, 10 dez. 07 jun. 01 Tendências e Debates, Caderno Brasil, p.3.
} 


\section{Trabalhonecessário}

ISSN: 1808 - 799X

ANO 12, № $19-2014$

Nesse contexto, cabe realçar que nos artigos de Grajew reside todo um conjunto de argumentos e análise utilizados para legitimar suas teses, que reforçam o convencimento no tecido social do projeto do setor industrial e o movimento para estabelecer uma agenda pública pautada por questões que venham ao encontro de suas demandas. Entre essas questões, podemos destacar a requisição de uma educação voltada para as novas exigências no mundo do trabalho, a crítica à política econômica do governo FHC e a defesa da implantação das reformas da previdência, trabalhista, tributária e uma gestão mais eficiente no Estado, como pontos essenciais para o processo de desenvolvimento do país. Nessa linha, cabe destacar que o discurso de Grajew legitima a presença do empresariado industrial dentro do aparelho de Estado ou ainda estabelecendo parcerias com o governo.

Por fim, não poderíamos deixar de tratar a questão da relação entre educação e problemas sociais, sem dedicarmos algumas linhas ao pensamento presente nos artigos de um dos empresários mais conhecidos do país, Antônio Ermírio de Moraes.

No tratamento empírico sobre as nossas fontes, verificamos que esse empresário dedicou 32 artigos ao debate dos problemas sociais existentes no país, sendo que em 17 desses textos a educação aparece como elemento vital para o combate à problemática social. Como no caso dos artigos dos outros representantes do setor industrial, nos textos contendo a mediação da educação na resolução dos problemas sociais, prevalece a temática da violência a que são expostos os jovens das comunidades carentes, o analfabetismo, a concentração de renda, a pobreza e a miséria presente na população brasileira.

Sobre a questão da desigualdade social no Brasil, e seus múltiplos reflexos na sociedade brasileira, Antônio Ermírio chama atenção sobre o seu caráter sistemático, abordando não apenas seus reflexos na população, como também para o conjunto de medidas no enfrentamento dessa questão. Num texto publicado no final de 2001, faz uma crítica vigorosa à globalização, citando dados 


\section{Trabalhonecessário}

ISSN: 1808 - 799X

ANO 12, № $19-2014$

da Organização Mundial do trabalho (OIT), dizendo que, enquanto nos últimos 30 anos o PIB do mundo cresceu em média $2,3 \%$ ao ano, a pobreza cresceu $1000 \%$, com a expansão da economia se concentrando nos países capitalistas centrais enquanto a pobreza ampliou nos países da periferia desse sistema, como o nosso (MORAES, 2001, p.2). Diante desse quadro, esse empresário prega para reversão dessa situação a adoção das reformas estruturais ${ }^{19}$ e a adoção de modificações e investimentos em duas áreas: "[...] Muitos especialistas já começaram a delinear o tipo de estímulo que pode ser mais eficaz na promoção do desenvolvimento dos países mais pobres. É quase unânime a ênfase na educação e na saúde .(...)" (MORAES, 2001, p.2).

Noutro texto (MORAES, 2004, p.2), diante dos dados de uma pesquisa do IBGE que comprova o retrocesso no quadro social brasileiro no período 19802000, o presidente do Grupo Votorantim foi categórico: “[...] É claro que, por trás de tudo, há uma causa muito séria que é o baixo nível educacional do nosso povo. (...) A educação é a mola do progresso. A sua falta é a causa do atraso. (...) (MORAES, 2004, p.2)". Sob esse ponto de vista, debatendo os males do analfabetismo funcional e o crescimento da mortalidade infantil e da gravidez na adolescência, Antonio Ermírio advoga que a educação representa o salto qualitativo na resolução da equação do problema social brasileiro, cabendo a nos sermos: "[...] Ousados e corajosos. Precisamos cortar na carne tudo que for necessário para educar bem os professores, equipar adequadamente as escolas e garantir bolsas de estudos para crianças que abandonam os estudos por motivos econômico" (MORAES, 2004, p.2).

\footnotetext{
19 Essas reformas seriam: Administrativas, Estado (adoção de uma gestão capitalista na sua condução), Política, Tributária e aprofundamento da reforma da previdência. Apesar de não termos citado, todos os representantes do setor industrial também defendem essas reformas ditas estruturais.
} 


\section{Trabalhonecessário}

ISSN: 1808 - 799X

ANO 12, № $19-2014$

Não obstante a essa relevância imputada à educação na questão dos problemas sociais brasileiros, o trabalho empírico apontou uma singularidade no debate dessa temática nos artigos de Antônio Ermírio em comparação com o dos outros representantes do setor industrial: não há cita os termos responsabilidade social da empresa ou cidadania empresarial, muito menos referência à participação do empresário na resolução dos problemas sociais. Essas abordagens, como vimos, são elementos que povoam e caracterizam boa parte dos artigos dos outros representantes do setor industrial, envolvendo a discussão sobre a forma de se tentar reverter o desfavorável quadro social brasileiro. Porém, isso não deve ser visto como uma distinção ou um confronto de princípios sobre a lógica que deve reinar na conformação da maneira de atuação predominante dos agentes sociais e políticos, em relação à questão social. Pelo contrário, mesmo não utilizando esses termos, Antônio Ermírio busca legitimar nos seus artigos o fato de que a resolução dos problemas sociais, como também da educação, não pode ficar a cargo apenas do Estado, sendo fundamental a participação de toda sociedade nesse processo. Ademais, em alguns artigos, destaca que o modelo do programa comunidade solidária é a forma ideal para que o país caminhe de maneira consistente na resolução dos seus problemas sociais. Por exemplo, num artigo, fazendo uso da personagem Joaninha para discutir o problema do analfabetismo, Antônio Ermírio demonstra essa posição:

\footnotetext{
Mas nada está perdido. O programa alfabetização solidária, por exemplo, conseguiu resultados espetaculares com crianças, adolescentes e adulto dos municípios mais pobres do Brasil. E em pouco tempo. (...) Em apenas 6 anos ( 1997 a 2003 ), foram atendidos 4 milhões de brasileiros, em 2010 municípios, com a ajuda de 135 parceiros e de 219 instituições de ensino - tudo feito sem alarde e sem marketing.

(...) A joaninha estava a par de tudo isso. Sempre gostou de coisas simples e que valorizam o contato direto entre professores e alunos. Isso é essencial. O resto é propaganda. Por essa razão, compartilho sua opinião: $O$ Brasil deveria continuar nessa linha de eficiência e austeridade em lugar de inventar novidade que cativam a mídia e encantam os demagogos, mas,
} 


\section{Trabalhonecessário}

ISSN: 1808 - 799X

ANO 12, № $19-2014$

infelizmente, desolam cidadãos (MORAES, 2003, p.2).

Desta forma, mesmo não reproduzindo determinado discurso presente em outros artigos dos representantes do setor industrial, Antônio Ermírio fortalece a visão da educação como instrumento central para a suplantação dos problemas sociais e reforça a ação de grupos que atuam na sociedade, de forma pontual, como caminho para que esse objetivo seja alcançado.

\section{CONCLUSÃO}

O levantamento empírico resultante do nosso trabalho, demonstra que no período pesquisado há um predomínio dos artigos dos representantes do setor industrial, frente ao do setor financeiro e do setor comercial e de serviços, produzindo 68 dos 72 artigos dos representantes do setor do empresariado, que estabeleceram uma relação entre educação e a resolução dos problemas sociais brasileiros, publicados no jornal Folha de São Paulo, no período coberto pela nossa pesquisa. Mas pelo que tentamos demonstrar, essa discrepância quantitativa não revela uma discordância de embate de propostas. Pelo contrário, o papel imputado a educação no combate aos problemas sociais e a fórmula baseada na participação dos empresários, através da responsabilidade social ou no tripé setor privado, Estado e terceiro setor, presente na maioria dos textos das representantes do setor industrial, também se reproduz nos artigos dos representantes dos dois setores que foram estudados. Nesse sentido, com relação à temática educação e a questão dos problemas sociais, podemos apontar que os representantes do setor industrial, trabalharam como intelectuais orgânicos de todo setor empresarial, procurando legitimar e reforçar essa tese como consenso ativo na agenda da sociedade civil e da sociedade política. Em suma, procuraram dar a reprodução social capitalista no 


\title{
Trabalhonecessário
}

ISSN: 1808 - 799X

ANO 12, № 19 - 2014

Brasil, uma nova sociabilidade que objetiva conformar o embate aos problemas sociais na lógica neoliberal, como podemos ver a partir dessa afirmação de Montaño (2002):

\begin{abstract}
(...) particularmente, a estratégia neoliberal tende a instrumentalizar um conjunto de valores, práticas, sujeitos, instâncias: o chamado "terceiro setor", os valores altruístas da "solidariedade individual" e do "voluntarismo" e as instituições e organizações que em torno deles se movimentam. $O$ capital luta por instrumentalizar a sociedade civil - torná-la dócil, desestruturada, desmobilizada, amigável. $O$ debate sobre 0

"terceiro setor", como ideologia,transforma a sociedade civil em meio para o projeto neoliberal desenvolver sua estratégia de reestruturação do capital,(...) (MONTAÑO, 2002, p 223)
\end{abstract}

Sob a lógica desse projeto, passasse a se atingir a idéia de direito dos cidadãos como valor universal e fortalecesse o processo de desresponsabilização do Estado na intervenção social, ao mesmo tempo em que recrudesce a cultura de se atuar dentro daquilo que for possível, de acordo com as condições existentes, e da auto-responsabilidade dos indivíduos por não conseguirem suplantar os problemas existentes (MONTANO, 2002, p. 232 a 241).

Nesses termos, pode-se dar uma maior entendimento para o crescimento dado aos representantes do empresariado industrial a temática da resolução dos problemas sociais, através do uso da educação. Comparando o período do primeiro governo FHC com o segundo governo tucano e o primeiro governo Lula, há um aumento de aproximadamente três vezes o número de artigos inseridos na categoria crescimento econômico, com abordagens sobre educação, passando de 33 textos para102, enquanto nos artigos referentes aos problemas sociais aumentou 11 vezes, pulando de seis para 68. Esses dados mostram o avanço da importância depositada na questão dos problemas sociais pelos intelectuais orgânicos do setor industrial e o quanto estão envolvidos na construção de uma nova sociabilidade regida pela lógica neoliberal, em termos de tratamento dos problemas sociais. Portanto, os artigos dos representantes do setor industrial de- 


\section{Trabalhonecessário}

ISSN: 1808 - 799X

ANO 12, № 19 - 2014

vem ser visto mais na dimensão qualitativa, do que quantitativa, porque são instrumentos no conjunto de relações de forças que tentam conformar na sociedade civil e na sociedade política, um projeto social mais afeito aos interesses do empresariado.

Com a proposta de combate aos problemas sociais, com o uso da educação, tendo como pressuposto a união entre o setor empresarial, terceiro setor e o Estado, a burguesia brasileira tem como inserir a questão social não mais como algo que deva ser escamoteado ou tratado com caridade, filantropia ou assistencialismo. Por esse projeto, a burguesia tem a condição de se apropriar desses problemas sociais, em sua maioria fruto de sua própria acumulação de riqueza, para legitimar o sistema capitalista e as formas de ascensão social dentro do uma nova sociabilidade ditado pela lógica do capital, reforçando as bases desse sistema na sociedade brasileira. Em outras palavras, pela primeira vez na história brasileira, a burguesia tem em suas mãos as condições de se apropriar de bandeiras dos setores progressistas ou de esquerda, como a luta contra a pobreza, a miséria e a concentração de renda, para criar um consenso na sociedade sobre o seu projeto de mundo. Como diria Gramsci, para atuar como classe dirigente na sociedade, dando a visão intelectual, moral e político para a resolução dos problemas sociais.

\section{REFERÊNCIAS}

GRAMSCI, Antonio. Cadernos do Cárcere, Vol. 2: Os intelectuais. O princípio educativo. Jornalismo. Rio de Janeiro: Civilização Brasileira, 2000 (a), p. 20 e 21. GERDAU, Jorge. Educação versos indignação. Folha de São Paulo. São Paulo, 25 jun 06a. Opinião Econômica, Caderno Dinheiro, p.2.

. Solidariedade e democracia. Folha de São Paulo. São Paulo, 10 dez. 06b, Opinião , Caderno Dinheiro, p.2

MATIAS, Antonio Jacinto. Folha de São Paulo. São Paulo. 15 ago. 06, Tendências e Debates, Caderno Brasil, p.3 


\section{Trabalhonecessário}

ISSN: 1808 - 799X

ANO 12, № $19-2014$

MARX, Karl e ENGELS, Friedrich. Manifesto do Partido Comunista.. (In) COUTINHO, Nelson. (org.). O manifesto comunista 150 anos depois. São Paulo: Fundação Perseu Abramo, 1998.

MONTAÑO Carlos. Terceiro Setor e a questão social: crítica ao padrão emergente de intervenção social. São Paulo: Editora Cortez, 2002, p.223

MORAES, Antonio Ermírio. Leia, reflita e julgue. 02 dez. 01. Folha de São Paulo. São Paulo, 02 dez 01, Opinião, Caderno Brasil, p.2

. Ajuda a nação estudando muito. Folha de São Paulo. São Paulo. 05 jan 03. Opinião, Caderno Brasil, p.2.

. Mais do que nunca, educação! Folha de São Paulo. São Paulo. 18 abr 04. Opinião, Caderno Brasil, p.2.

Ruy M. Altenfelder. Marx, Engels e a vaca de Sarandi. Folha de São Paulo. São Paulo, 23 dez. 02, Tendências e Debates, Caderno Brasil, p.3

SALLES, Pedro Moreira. A transformação fundamental. O Globo. Rio de Janeiro. 10 jul. 00, Opinião, Caderno País, p.7.

SENNA, Viviane. Indignação positiva. Folha de São Paulo. São Paulo, 14 mar. 20, Tendências e Debates, Caderno Brasil, p.3

. Desenvolvimento humano. Folha de São Paulo. São Paulo, 25 ago. 02, Tendências e Debates, Caderno Brasil, p.3

STEINBRUCH, Benjamim. Do Adnann ao nosso Zé. Folha de São Paulo. São Paulo, 19 out. 99a., Opinião Econômica, Caderno Dinheiro, p.2. . Uma aposta que não podemos perder. Folha de São Paulo. São Paulo, 28 dez. 99b. Opinião Econômica, Caderno Dinheiro, p.2.

. Prioridade Humana. Folha de São Paulo. São Paulo, 28 dez. 99c. Opinião Econômica, Caderno Dinheiro, p.2.

Pobre lucro pobre.. Folha de São Paulo. São Paulo, 28 out. 99d. Opinião Econômica, Caderno Dinheiro, p.2.

SZAJMAN. Abram. Crime de lesa-esperança. Folha de São Paulo. São Paulo, 01 out. 03, Tendências e Debates, Caderno Brasil, p.3

. Sesc e Senac em perigo. Folha de São Paulo. São Paulo, 02 ou. 06, Tendências e Debates, Caderno Brasil, p.3 